\title{
SUJEITOS COLETIVOS DO CAMPO, TERRITORIALIDADE DO ALIMENTO E CONSTRUÇÃO SOCIAL DOS DIREITOS
}

\author{
Marina Rocha Moreira* \\ Eduardo Gonçalves Rocha**
}

\begin{abstract}
Resumo: Com o surgimento das empresas agroalimentícias, não há que se olvidar que os alimentos foram paulatinamente territorializados pelo capitalismo e, aos poucos, foram invisibilizando os sujeitos do campo, retirando parcela de sua reprodução social e de suas culturas. Entretanto, é sabido que as múltiplas territorialidades são essenciais na construção do direito, inclusive no que pertine aos alimentos. Através de uma análise qualitativa por meio de artigos e referencias bibliográficos, e pelo método hipotético dedutivo, será analisado como toda essa dinâmica de conflitualidade pelos alimentos pelas empresas agrárias, interfere na construção social do direito do campo pelas múltiplas territorialidades dali originárias.
\end{abstract}

Palavras-chave: Territorialização; alimentos; sujeitos coletivos; construção social de direitos; direitos humanos.

\section{COLLECTIVE SUBJECTS OF THE FIELD, TERRITORIALITY OF FOOD AND SOCIAL CONSTRUCTION OF RIGHTS}

\begin{abstract}
From the emergence of agri-food companies, it'd no doubt that food was gradually territorialized by capitalism and, slowly, the subjects of the countryside became invisible, removing part of their social reproduction and their cultures. However, it's well known that multiple territorialities are essential in the construction of law, including in what concerns food. Through a qualitative analysis through articles and bibliographical references, and by the hypothetical deductive method, it will be analyzed how all this dynamics of food conflict by agrarian enterprises, interferes in social construction of the law of the field by the multiple territorialities from which they originate.
\end{abstract}

Keywords: Territorialization; food; collective subjects; social construction of rights; human rights.

\footnotetext{
${ }^{*}$ Marina Rocha Moreira -É graduada em Direito pela Pontifícia Universidade Católica de Goiás. Possui graduação latu sensu em Direito Público pela Faculdade Damásio de Jesus. É graduanda strict sensu (mestrado) em Direito Agrário pela Universidade Federal de Goiás. Pesquisa Territorialização dos alimentos. Docente efetiva no Centro Universitário de Goiatuba - UniCerrado. Endereço eletrônico: marinarochamoreira@ hotmail.com

${ }^{* *}$ Eduardo Gonçalves Rocha - Graduado em Direito pela Universidade Federal de Goiás. Mestre e Doutor em Direito pela Universidade de Brasília. Pesquisa Direito à alimentação, Ecologia política e pesquisa qualitativa. Docente de graduação e pós-graduação em Direito da Universidade Federal de Goiás. Endereço eletrônico: eduardofdufg@yahoo.com.br
} 


\section{I - INTRODUÇÃO}

Não importa a denominação. Empresa agrária, empresa rural, agricultura capitalista ou agricultura patronal, chegando até mesmo o "famoso" agronegócio. Todas essas nomenclaturas nada mais são do que a representação da empresa agrária, instituto esse que vem ganhando proeminência no cenário contemporâneo diante da expansão do capital no campo (CAMACHO, 2012, p. 4).

Para a melhor compreensão do tema, é importante salientar que a empresa agrária deposita forte carga economicista nas relações agrárias, se pautando pela elevada produtividade e se valendo da organização de bens e tecnologias de ponta, com o fulcro de produzir gêneros excedentes que ficarão à disposição do mercado. Assim, a empresa agrária carrega em si forte carga capitalista, abandonando às questões essencialmente agrárias que de fato primam pela relação de cultura do homem com a terra (CAMACHO, 2012, p. 4).

Entretanto, é sabido que esse avanço da empresa agrário no cenário campesino é temerário quando levamos em consideração as múltiplas territorialidades que ali se encontram e mais ainda quando pensamos na construção social dos direitos desses povos. Isso porque tal empresa invisibiliza as mencionadas classes populares campesinas, o que ressalta a importância da mobilização e organização das mesmas com o intuito de criar práticas sociais e políticas que lhes darão espaços na sociedade e assim, esses atores terão a possibilidade de criar direitos que lhes abarcarão (JÚNIOR, 2008, p. 270).

Paralelo a este cenário, é necessário salientar que os direitos são construídos por uma processualidade em que múltiplos sujeitos estão envolvidos. Assim, o direito humano a alimentação consagrado na Constituição Federal brasileira deve ser compreendido como um conjunto de lutas processualizadas e positivadas institucionalmente para proteger o cidadão contra a postura hegemônica do Estado na vida dos particulares e na interferência ilimitada do mercado nas relações sociais e as consequências dessas no mercado capitalista (FLORES, 2018, p. 42).

Quando remetemos a expansão territorial das empresas agrárias sobre o campo e sobre os alimentos, é preciso compreender que como contra-movimento existem várias identidades coletivas emergentes e que trazem através de suas experiências, significações próprias sobre os alimentos e as relações dele decorrentes que são capazes de afirmar e construir direitos naquele cenário (JÚNIOR, 2008, p. 270-271). 
Deste modo, inobservada a multiplicidade de sujeitos e sua construção social e cultural, a territorialização dos alimentos se torna excludente e passa a negar uma diversidade de direitos através da relação de poder instalada pelo capital no cenário campesino (PORTOGONÇALVES, 2017, p. 288). Isto posto, propõe-se a seguinte problemática para o presente trabalho: como a territorialização dos alimentos infere na construção social dos direitos dos sujeitos coletivos do campo?

Através do método hipotético dedutivo, trazemos a hipótese de que toda essa dinâmica de conflitualidade pelos alimentos pelas empresas agrárias, supostamente interfere na construção social do direito do campo pelas múltiplas territorialidades que dali são originárias. Assim, os grupos campesinos que se constituem por meio de suas respectivas culturas, formando por consequência seus territórios, estão sendo excluídos e desqualificados diante do padrão imposto com base na experiência de países hegemônicos (PORTO-GONÇALVES, 2017, p. 277).

Diante do problema jurídico proposto, se estruturou o presente artigo em 03 (três) sessões para a melhor compreensão do tema. Na segunda sessão será abordado o processo de territorialização dos alimentos pelas empresas agrárias. Nesse momento será demonstrado como o sistema do capital é capaz de gerar conflitualidades no campo, surgindo territórios que ficam à disposição para lhe servir, de modo à invisibilizar sujeitos locais e suas respectivas culturas.

$\mathrm{Na}$ terceira sessão se demonstrará como as múltiplas territorialidades do campo resistem na expansão da globalização neoliberal e do capitalismo sobre os alimentos e no campo. Assim, vamos explicar como esses sujeitos coletivos, dotados de saberes específicos e de suas culturas peculiares, são importantes atores para a transformação do cenário não só social, mas também por atingir o processo normativo, político e jurídico hoje já instalado, por meio de um processo contínuo de lutas e resistências territoriais.

A construção social dos direitos dos sujeitos coletivos do campo, conforme já salientado, se dá através de um processo dinâmico de resistência contra a territorialização de poderes hegemônicos instalados do campo. A luta por visibilidade, recuperação de suas autonomias e o resgate cultural de cada povo é essencial para a demarcação das territorialidades e a construção de direitos pela própria sociedade campesina, inclusive no que pertine aos alimentos. Esses temas serão abordados na última sessão deste trabalho.

Por fim, cabe ressaltar que o presente artigo utilizou como seguimento metodológico o estudo do tema abordado através de leituras e revisões bibliográficas de periódicos, 
dissertações, livros, artigos e teses, dentre outras seleções que forem atinentes ao tema. Com o objetivo de explorar e esclarecer as principais questões divergentes ao caso foram realizadas pesquisas qualitativas e análises descritivas referentes aos alimentos, sujeitos coletivos e a questão da territorialidade. As aludidas pesquisas foram debruçadas nos objetos já suscitados bem como em sites pela rede mundial de computadores, os quais ofereceram respaldo para a formulação de hipótese conforme o método hipotético-dedutivo.

\section{II - TERRITORIALIZAÇÃO DOS ALIMENTOS}

A agricultura familiar e o agronegócio são realidades distintas, mas que ambas ainda sobrevivem no mesmo cenário. Todavia, importante ressaltar como as grandes empresas se valem dos negócios que são feitos a partir da subsunção das atividades agrárias/agrícolas ao seu modo de produção para expandirem seus territórios, com o objetivo de aumentar seus rendimentos e com a produção voltada para a economia de mercado (TRENTINI, 2001, p. 238239).

Aqui, quando se trata de territórios, é preciso compreender que este vai além da merca circunscrição de espaço de determinado local. Os territórios vão além de meros espaços determinados milimetricamente, sendo condições espaciais para o desenvolvimento de relações sociais que surgem diante das mais diversas conflitualidades que vão surgindo diante do desenvolvimento e a organização das sociedades (FERNANDES, 2008, p. 35).

Assim, são a partir das relações sociais que são produzidas em bases espaciais específicas é que originam os mais diversos territórios e as conflitualidades surgidas dessas interações sociais também são de suma importância para a delimitação de cada território. Todos os conflitos, sejam eles de ordem econômica, politica, ideológica, teórica ou cultural, são significativos para a demarcação das territorialidades (FERNANDES, 2008, p. 36).

O capital, seguindo a ordem de formação de territórios, ganhou espaço social quando o seu modo de reprodução passou a gerar conflitualidades. Dai, começaram a surgir os territórios capitalistas e os modelos de resistência à intencionalidade de sua reprodução. Isso porque, muito embora os territórios formados pelo modo de reprodução capitalista encontram um modelo de resistência social que é contrário à sua perpetuação e consagração no meio e, por meio das conflitualidades, passam a criar um cenário de resistência (FERNANDES, 2008, p. 36). 
Pensar em uma economia capitalista perpassa pelo entendimento de uma constante disputa por conquista de mercados. O que se guerrilha é não somente por espaços para venda de produtos, mas principalmente por controle de espaços e regiões propícios para a produção de matérias primas à indústria ou até mesmo pela obtenção da própria fonte de tais bens (PORTO-GONÇALVES, 2017, p. 32).

A forma de produção pautada pelo capital no que pertine ao campo, expropriou os trabalhadores das suas condições de trabalho na agricultura, os subordinando ao novo cenário capitalista que prima pelas relações de lucro e comércio. Assim, os alimentos advindos dessa agricultura foram se adaptando àquele modo de produção, passando a agregar valor não só ao trabalho humano nele empenhado e à natureza a ele disponível, mas ainda com o fulcro de acumulação para gerar lucros e valor de mercado, resultando no que é conhecido como commodities.

Os alimentos, deste deita, foram gradativamente atingidos pelo modo de reprodução do capital e sua territorialização foi uma consequência das conflitualidades surgidas entre as empresas capitalistas e os sujeitos do campo. A terra e tudo o que paira sobre ela, qual seja, os alimentos, foram transformados pelas empresas agrárias em sua concepção e levados a estado de coisa, surgindo sobre elas especulação de preço e ficando a disposição do mercado. Os alimentos deixaram de ser parte cultural e fonte de vida e passaram a serem valores negociáveis ou meras mercadorias (SOUZA FILHO, 2015, p. 58).

Remonta-se, assim, que os alimentos não são produzidos tão somente para a satisfação da compleição física e nutricional dos indivíduos e tampouco constituem parte de decisão pessoal e isolada de cada ser humano para seu consumo. Os alimentos são frutos de um processo coletivo, consagrados da esfera pública, podendo ser um marco característico e que serve de integração para as mais diversas categorias sociais (DERANI, 2005, p. 55).

As técnicas empregadas na produção dos alimentos sofreram uma evolução a medida da inserção de novos elementos nas fases produtivas. Assim, inicialmente os alimentos eram produzidos conforme a disponibilidade natural e a cultura do homem local empregada para tanto. Todavia, com o surgimento de maquinários e tecnologias, os alimentos perderam sua essência de produto eminentemente cultural, passando a agregar valor técnico. Deste modo, a cultura passou a subsumir aos imperativos do mercado e os alimentos perderam suas características originais, através da uniformização de sabores, pelo aumento da durabilidade e atratividade dos rótulos e embalagens nos mercados (SANTOS, 1999, p. 157-159). 
Vale relembrar que os alimentos são direitos humanos, mas que, inevitavelmente perpassam pela lupa dos territórios, uma vez que as empresas agroalimentícias, se valendo do modo de produção pautado pelo capital, se apropriaram desse espaço de produção, inivisibilizando e retirando, por vezes, as possibilidades de escolha e determinação cultural dos sujeitos tradicionais do campo, atingindo a soberania e segurança alimentar desses povos. Os alimentos, assim como qualquer outro direito humano, não podem ser reduzidos como meras normas positivadas ou discursos conservadores diante do cenário de territorialização hodierno, devendo ser um dever autoimposto nas lutas sociais pela dignidade de cada categoria e de cada cidadão (FLORES, 2009, p. 20-21).

Todo esse processo de territorialização dos alimentos e do que se é produzido em nossas terras, muito embora seja acobertado por um discurso de "modernização do campo" através da inserção de insumos e instrumentos tecnológicos para o suposto aumento da produtividade, trás consequências nefastas para os sujeitos e para o próprio cenário campesino. Isso porque, o sistema fundiário das empresas agrárias insurge ainda mais o sistema fundiário de concentração de terras e rendas, que agrupados com a exploração do ser humano e com a destruição da natureza, demonstram a verdadeira realidade do modelo capitalista inserido no campo (CAMACHO, 2012, p. 4).

Com a mecanização do campo e a intensificação de maquinários no meio rural com o intuito de reduzir mão de obra possibilita que cada vez mais os sujeitos locais sejam invisibilizados e retiradas as suas possibilidades de emprego no campo. Soma-se ainda a este modelo de produção característica da monocultura, produção de um único tipo de insumo agrícola, com o fulcro de acumulação e especulação de lucros sobre a produção, gerando o que hoje é conhecido por commodities. A monocultura conta ainda com o uso intensivo de adubos e agrotóxicos para potencializar sua produção, todavia coloca em risco a biodiversidade local diante da padronização dos ecossistemas, colocando ainda em risco a saúde humana (CAMACHO, 2012, p. 6-7).

Com a inserção de novos insumos químicos e fertilizantes pela segunda revolução agrícola moderna, os produtores rurais cada dia mais foram se afastando da produção para o autoconsumo, especializando-se na monocultura conforme as condições locais de produção e também por ocasião da localização das indústrias de transformação dos insumos ora produzidos. Tal fator de produção visa atender os imperativos mercadológicos e causa apontamento de distinções naturais entre as propriedades, salientando aquelas que contam com solos mais férteis em detrimento das demais (SANTILLI, 2009, p. 56-57). 
Através do processo de substituição dos produtos agrícolas pelos industriais e a medida que a indústria se apropria de fertilizantes químicos e de rações para alimentar animais e gerir o campo, os agricultores foram paulatinamente excluídos da produção dos novos bens agrícolas, atividades essas que foram assumidas por pesquisadores, de modo que as práticas tradicionalmente utilizadas pelos produtores rurais passaram a ser consideradas inadequadas diante dessa modernização agrícola (SANTILLI, 2009, p. 57-58).

O agronegócio, tendo como representante expoente a empresa agrária, é um resultado da territorialização dos espaços rurais e que tem como escopo o negócio da produção agrícola, a disposição para o mercado de todos os produtos que ali foram gerados, com o mero intuito de gerar propulsão econômica, seguindo a origem etimológica de sua palavra. Em contrapartida, analisando o que se entende por agricultura, compreende-se que esta é intimamente ligada com a cultura e o modo de subsistência e reprodução de populações tradicionais, as quais integram o patrimônio cultural e social do país (PORTO-GONÇALVES, 2004, p. 46).

Desta forma, é preciso reanalisar todo o cenário agrário e as relações que ali se constituem. Não mais merece prosperar o cenário economicista que se instalou pelo modo de produção capitalista que invisibiliza os sujeitos do campo, suas culturas e que gere transtornos e desigualdades. É preciso reanalisar todo o cenário através de um viés humanista, com valores de justiça, paz, igualdade entre os seres humanos para que assim aja a consolidação de uma convivência harmônica entre os povos em que sejam compatibilizados os valores econômicos, sociais e culturais entre eles (ZELEDÓN, 2005, p. 80-81), conforme proposta trazida na próxima sessão.

\section{III - MÚLTIPLAS TERRITORIALIDADES: OS SUJEITOS COLETIVOS DO CAMPO}

A territorialização capitalista dos alimentos deposita forte carga de poder quando transforma um direito humano fundamental em mera mercadoria, colocando em risco até mesmo a democracia, uma vez que aquela é definida pela sua dimensão econômica e financeira e, por vezes, não se importa com outros e novos sujeitos nesse modo de produção (PORTOGONÇALVES, 2017, p. 131). Desta feita, essa mercantilização da natureza unifica não só o modo de produção dos alimentos, mas também busca uniformizar os sabores e os saberes das mais diversas culturas e sujeitos, em detrimento de uma homogeneização de produtos nas prateleiras dos supermercados a favor das grandes empresas do ramo agroalimentício (PORTOGONÇALVES, 2017, p. 108).

Rev. de Direito Agrário e Agroambiental | e-ISSN: 2526-0081 | Porto Alegre | v. 4 | n. 2 | p. 91 - 107 | Jul/Dez. 2018 
Assim, quando falamos em territorialização dos alimentos pela ordem do capital de produção devemos compreender que essa nada mais foi do que um resultado de ideologias e correntes políticas dominantes que se apropriaram de um direito humano fundamental (GOHN, 2018, p. 3). O território, dessa forma entendido, agrega na sua materialidade uma divergência entre os mais diversos modos de apropriação do espaço, de modo que quando pensamos na lógica mercantil, ou seja, aquela pautada pelo dinheiro, "implica uma dinâmica espacial que des-envolve os lugares, regiões e seus povos e culturas e, deste modo, instaura tensões territoriais permanentes" (PORTO-GONÇALVES, 2017, p. 129).

Em contrapartida, devemos ressaltar que a ideia de território não deve mais se enquadrar apenas em crenças ideológicas difundidas, de modo que houve uma ressignificação de seu conceito, o qual passa a considerar a territorialidade, o espaço físico em que cada grupo social vive, consagrando sua cultura própria, seus modos específicos de produção, sua linguística característica, o seu contexto socioeconômico, levando em consideração sua etnia e ancestralidade, e ainda a política inerente de cada espaço geográfico (GOHN, 2018, p. 3).

Para compreendermos as múltiplas territorialidades campesinas que também vivem da produção de alimentos, devemos partir do pressuposto do que são os sujeitos que as compõe. Assim, importante é a contribuição que José Geraldo de Souza Júnior (2008, p. 259) nos trás em sua tese de doutorado, momento no qual dispõe que "o sujeito deve ser definido a partir da idéia de indivíduo como agente, ou seja, imbricado em sua condição social" [sic]. Dessa premissa, podemos compreender que os sujeitos estão para a sociedade como agentes de contestação da ordem social e ao positivismo trazido pela modernidade.

Diante das transformações sociais, políticas, históricas, econômicas, jurídicas e culturais é que surge o sujeito. Desta feita, é impossível pensar na existência de um sujeito, sem que antes ocorra uma processualidade de eventos contínuos que sejam capazes de instaurar conflitualidades na sociedade. Os sujeitos surgem como decorrência local das mudanças ocorridas, como forma de contestação e informação, e passam dar sentido a realidade que os permeiam diante de suas potencialidades (JÚNIOR, 2008, p. 271-272).

Os sujeitos, organizados em determinado território, passam a ter com esse sentimento de pertença, formando grupos de semelhantes interesses, com compartilhamento étnico, religioso e comunitário. Esse sentimento de pertencimento se dá por meio de vínculos formados entre esses sujeitos, por meio de um processo continuo de reflexividade sobre os mais diversos territórios e o contexto social no qual estão inseridos, e assim são capazes de construir signos e 
sentidos para suas próprias ações dentro desse espaço coletivo de pertença compartilhado (GONH, 2018, p. 4).

O cenário neoliberal, advindo com o processo de globalização capitalista, é um marco quanto à afirmação do indivíduo como sujeito pessoal. Isso porque as imposições trazidas pelo mercado insurgem nos sujeitos aspirações de libertação individual quanto ao modelo econômico imposto, sujeitos esses que agora passam a reivindicar democraticamente seus direitos individuais e o reconhecimento do outro perante a sua cultura, destacando a dimensão cultural desses direitos pelos quais buscam tutela (JÚNIOR, 2008, p. 260).

Para o reconhecimento mútuo de culturas e identidades coletivas, é preciso o diálogo intercultural entre tais sujeitos. As sociedades, os grupos e os indivíduos se organizam assim como sujeitos coletivos em prol da integração não só de suas economias e da política, mas principalmente de projetos culturais, indo além das noções de tempo e espaço que adotam, ou seja, pressupõe a formação de múltiplas territorialidades integradas culturalmente entre si (JÚNIOR, 2008, p. 261).

Esses sujeitos coletivos passam a adotar postura criativa e com capacidade de transformações e inovações diante dos conflitos sociais. Deste modo, essas redes sociais de sujeitos passam a formar uma identidade coletiva na qual cada individuo e grupo, com suas peculiares experiências sociais, são fundamentais na criação de novos modelos culturais. E isso se dá principalmente por meio da oposição às tomadas de decisões políticas da ordem já instalada e na exposição de modelos culturais alternativos advindos dessas ações coletivas (JÚNIOR, 2008, p. 263).

Tal manifestação e criação de novos modelos culturais são essenciais para o reconhecimento de direitos coletivos e patrimoniais de sujeitos e territorialidades imbricados de conhecimentos culturais milenares. Tais conhecimentos vêm sendo invisibilisados diante daqueles produzidos por grandes empresas em laboratórios, contando ainda com o suporte estatal para tanto, colocando em risco e, por vezes, pormenorizando, o conhecimento patrimonial e coletivo de comunidades camponesas, indígenas, quilombolas, dentre outras, afastando assim os saberes desses povos, principalmente quando se trata da produção de alimentos (PORTO-GONÇALVES, 2017, p. 218-219).

O cenário de globalização trouxe não só a mercantilização da natureza (que neste trabalho observamos através da territorialização capitalista dos alimentos), mas também levou as diversas identidades á uma homogeneização de suas culturas, fragmentando suas vidas sociais (JÚNIOR, 2008, p. 266). Dai a importância do ativismo e do empoderamento dos 
sujeitos coletivos em busca do reconhecimento de suas diversidades identitárias e da transversalidade das suas demandas por direitos. Nesse caminhar, importante a consideração que Porto-Gonçalves (2017, p. 264) pontua respeito do assunto:

(...) a crescente importância das lutas camponesas, indígenas e de tantas populações que reivindicam o direito ao território, à sua cultura, os direitos coletivos e comunitários sobre o conhecimento acerca de cultivares e de remédios e que hoje se unificam diante da ameaça de ter sua biotecnologia ancestral sendo poluída geneticamente por grandes corporações que, antes de tudo, visam seus próprios interesses e não da humanidade. Essas populações, até aqui vistas por muitos como atrasadas e condenadas à extinção, têm hoje importantes aliados nas grandes cidades. Afinal é o alimento que damos a nossos filhos que está correndo perigo, é a nossa reprodução que está em jogo.

Dessa colocação, retomamos o quão importante é a pluralidade de sujeitos na construção política dos espaços e mais ainda no que pertine a criação de direitos. Cada sujeito coletivo, enquanto identidade de contestação social e como fruto de interação social, permite o reconhecimento recíproco da multiplicidade de atores e de suas experiências, e o seu auto reconhecimento é capaz de lhe dar legitimidade para reconhecer suas demandas e trazer suas propostas de alterações sociais para, desta formar, esses sujeitos atuarem na cena política e criarem novos direitos (JÚNIOR, 2008, p. 268-269).

\section{IV- A CONSTRUÇÃO SOCIAL DOS DIREITOS}

Pensar em uma perspectiva de construção social dos direitos dos sujeitos coletivos exige o distanciamento continuo e cada vez maior da proposta da territorialização de espaços e culturas pelo poder hegemônico e dominante. Nesse sentido, os alimentos devem ser compreendidos a partir de um contexto histórico, cultural, social, econômico e político no qual a atividade agrária, acompanhando essas metamorfoses, passa por um processo contínuo de modificação (ZELEDÓN, 2005, p. 12).

Deste modo, principalmente os sujeitos dessas atividades devem ser constantemente observados, uma vez que diante das condições heterogêneas hoje instaladas no campo, é impossível não analisar a multiplicidade de sujeitos que estão envolvidas nas relações campesinas modernas na construção social de direitos, uma vez que não observadas, resultaria em um monopólio da jurisdição (ZELEDÓN, 2005, p. 12). Sobre o assunto, relevante foi o apontamento de Júnior (2008, p. 280) as diferentes ordens jurídicas hoje instaladas socialmente: 
(...) porosidades de diferentes ordens jurídicas, contrapondo-se à visão de unidade de ordenamentos, que obrigam a constantes transições e transgressões referidas a práticas sociais emancipatórias, nas quais as transgressões concretas são sempre produto de uma negociação e de um juízo político. Compreender, pois, a estrutura de um ordenamento como unidade hierarquizada de um ordem jurídica sujeita a um monopólio de jurisdição (...) resulta, em todo caso, em opção teórica e política de reconhecimento da validade e da legitimidade normativa desse modo produzida.

Muito embora as empresas agrárias, representadas aqui pelas companhias agroalimentícias, tenham retirado parte da aplicação do conhecimento tradicional no campo e influenciado o modo de produção das populações locais através do processo de territorialização pelo capital, sem dúvidas todos os sujeitos e comunidades, com seus saberes e regras populares, são essenciais para a construção social de direitos que propomos no presente trabalho. De tal modo, toda essa multiplicidade de sujeitos e culturas é fundamental na formação de um processo legislativo que seja democrático, que dê voz a toda essa diversidade na luta pela dignidade de cada categoria, formando espaços institucionais que fomentarão políticas públicas e influenciarão na consolidação dessas no mundo jurídico (SOUSA, et. al, 2018, p. 44-45).

O que ocorre é que a territorialização capitalista dos alimentos ocorreu diante de um processo histórico em que também se deu a construção social de direitos. E toda vez em que se remete a construção deste direito sempre se remete a um movimento ligado à vida dos homens e a multiplicidade de fatores e uma variedade de atores sociais envolvidos nas atividades agrárias. Todos esses sujeitos que, quando segregados e oprimidos no campo pelo processo de territorialização, passaram a reivindicar espaço na sociedade ao longo desse processo histórico, pugnando pelo reconhecimento de seus direitos, das suas culturas, e pleiteando para que suas pretensões fossem acolhidas não só no seio social, mas também por meio de um sistema normativo (SOUSA, et. al. P. 44-45).

Compreender o direito de uma multiplicidade de sujeitos do campo como meras normas positivadas em textos legais é cair no reducionismo em que transforma as leis em objeto de dominação dos atores que já sofreram com o processo de segregação no campo. O positivismo exacerbado enrijece e coloca em risco a existência da pluralidade de culturas, saberes, experiências e tradições dos sujeitos campesinos (FILHO, 1982, p. 31-32). Por este motivo é que se ressalta a importância das conflitualidades surgidas no processo de territorialidades, pois são por meio dessas contradições das aspirações sociais e das 
consequentes lutas para acesso aos bens e direitos de cada categoria é que se caminha para uma futura positivação jurídica (FILHO, 1982, p. 3-4).

Por isso é importante o resgate da participação da multiplicidade de sujeitos no resgate da democracia. Esse regime de governo só se implementa de fato quando observados e reconhecidos os direitos, os saberes, as tradições, a cultura de cada cidadão enquanto sujeito autônomo e dentro de sua categoria social. E aqui, quando tratamos de sujeitos autônomos, devemos lembrar que a autonomia é a possibilidade de cada qual criar suas normas, a possibilidade conferida a um sujeito de criar direitos e participar da direção social por meio de sua cidadania (JÚNIOR, 2008, p. 275).

Nesse caminhar, não há dúvidas de que as instituições já consagradas e positivadas são essenciais, mas é preciso ir além. É preciso caminhar além das normas já positivadas e que dão legitimidade tão somente a classe dominante que por ora a estabeleceu. Isso porque a democracia é formada fora das instituições (FILHO, 1982, p. 36).

A democracia é formada na rua, em espaços públicos e até mesmo no campo ou qualquer outro lugar que permita que os himens construam suas leis a partir de suas perspectivas e anseios subjetivos. Nesse sentido, importante a explanação de Costa (2018, p. 181) a respeito do tema. Senão vejamos:

A práxis constitucional que atualiza o direito não se faz somente por meio das instituições estatais. O direito se constrói e reconstrói no seio da sociedade, nas lutas dos movimentos sociais, nos espaços públicos onde cidadãos são dotados de autonomia pública e privada vivem sua autolegislação: na rua.

Nesse viés, a construção social de direitos pelos sujeitos coletivos do campo deve ser pautada pela democracia, em que a multiplicidade de atores e categorias sociais sejam visibilizados e que suas culturas, tradições e anseios sejam observados no momento de positivação legal. Mesmo porque não é mais possível ter como verdade única e absoluta tão somente aquilo que se tem positivado, sem antes se observar as situações de intolerância, injustiça e opressões, as quais são partes presentes e constantes na sociedade contemporânea. Acreditar na visão positiva excludente é permanecer em estado de atitudes antidemocráticas (FLORES, 2005, p. 70).

As lutas sociais pressupõe que, a partir de um consenso moral dentro de um meio social cooperativo, a resistência e o protesto são formas de reivindicar a lesão normativa desse consenso. Assim, tais lutas regulam, ainda que de maneira informal, a ordenação de deveres e 
direitos dentre os sujeitos dominadores e os dominados nas categorias sociais (HONNETH, 2003, p. 263).

O reconhecimento das lutas sociais por dignidade e reconhecimento de direitos sociais pelos mais diversos sujeitos que estão no campo é o primeiro passo para legitimação dos mesmos através da sistematização agrária. Esse processo de lutas para o acesso aos bens necessários para viver com dignidade é o ponto de partida da construção do direito pelos sujeitos coletivos do campo (FLORES, 2009, p. 28). As transformações sociais e econômicas advindas da territorialização alteram a compreensão do que é o próprio direito e invisibilizam os sujeitos do campo, quando o direito aqui é compreendido como uma processualidade em que os seus atores estão em busca da concretização e acesso àqueles bens (FLORES, 2009, p. 28-29).

Outro importante ponto a ser validado para a construção social de direitos é o reconhecimento recíproco entre os sujeitos. Todo grupo social luta, em tese, em busca de pretensões que os levem a uma vida digna, as quais coincidem com o reconhecimento de seus interesses e direitos, e que os legitimam perante um ordenamento jurídico. Esse reconhecimento jurídico deve se pautar pela necessidade do respeito coletivo recíproco, ou seja, é preciso que os sujeitos se reconheçam e se respeitem a medida dos limites culturais de cada grupo, limites esses que carregam elementos específicos que vão legitimar a dignidade de cada qual diante do sistema social e jurídico (HONNETH, 2003, p. 244-245).

Assim, é importante lembrar que os valores, assim como as relações jurídicas, estão sujeitos a um continuo processo de mudanças perseguindo cada vez mais o atendimento ao respeito universal ou a um senso de igualdade entre os homens. Deste modo, a dignidade é historicamente variável à medida que vão se desenvolvendo padrões de reconhecimento intersubjetivo entre os mais diversos sujeitos (HONNETH, 2003, p. 274).

O que se observa é uma transição paradigmática na construção social dos direitos, à medida que se caminha de uma visão normativista e substantivista do direito, que foi construída a partir de pressupostos teóricos, para uma construção de direitos pautada em uma dimensão processual, em que os direitos surgem a partir da análise de conflitualidades surgidas na sociedade e do reconhecimento intersubjetivo dos sujeitos coletivos, "rejeitando a matriz positivista de redução da complexidade ao formalismo legalista e de deslocamento dos pressupostos éticos que fundam uma normatividade legítima" (JÚNIOR, 2008, p. 285-287).

As relações sociais intersubjetivas se pautam pelos padrões de reconhecimento do próprio direito, uma vez que este estabelece por meio das normas uma solidariedade entre os sujeitos que transcendem categorias específicas, sendo moldes de valores de toda a coletividade 
(HONNETH, 2003, p. 278). A construção social dos direitos, assim, deve partir da premissa de que é essencial primar pela visibilidade dos sujeitos do campo, das populações tradicionais e de suas culturas, em um reconhecimento recíproco entre os atores sociais que constituem e constroem a verdadeira realidade do campo.

\section{CONSIDERAÇÕES FINAIS}

É sabido que a agricultura familiar no Brasil, consagrada essa pela multiplicidade de sujeitos e territorialidades diversas no campo brasileiro, tem sido a principal responsável pela produção de alimentos e pelo fomento das economias locais, sendo ainda vetor essencial para a segurança alimentar, gerando empregos e estimulando o crescimento de renda e o desenvolvimento local de modo sustentável. Todavia, não há que se olvidar que as empresas agrárias constituídas do processo de "modernização agrícola" trouxeram impactos significativos não só nos espaços rurais, de modo a gerar a padronização da produção e a concentração e especulação das terras mais férteis, como também gerou um êxodo rural e marginalizou a agricultura familiar, invisibilizando os sujeitos do campo (SANTILLI, 2009, p. 86-87).

Ressalta-se que cada Estado é responsável por reconhecer as especificidades e peculiaridades de seu povo, de modo que é ao mesmo que se atribui o poder de compartilhar tais conhecimentos com o restante da humanidade. Lembra-se ainda que este é um poder-dever dos Estados, uma obrigação atribuída aos mesmos para evitar que as empresas e grandes corporações interacionais se apropriem dos conhecimentos específicos locais e passem os explorar com valor mercadológico, territorializando assim os mais diversos espaços (CLAVERO, 2017, p. 187-188).

Nesse sentido, importante salientar que as comunidades e sujeitos tradicionais são a forma mais expressiva de se representar o passado em relação ao cenário real atual, de modo que ao se pensar no termo "tradicional" não se restringe a ideia de algo remoto e cristalizado pelo tempo, mas sim de um conhecimento que é constantemente atualizado, uma vez que pertence ao povo, de modo a não ser tendência para ciência e tampouco para os negócios dela decorrentes (CLAVERO, 2017, p. 191).

O Direito formado por essas populações e sujeitos tradicionais é uma processualidade em que tais povos estão em busca de condições materiais (e até mesmo imateriais) para ter acesso a bens que lhes dão dignidade para viver e que até então não estão positivados (FLORES, 
2009, p. 29). Assim, o Direito não se esgota como um arcabouço de normas positivadas, como meras regras e letras de leis fixas e estáticas (FILHO, 1982. P. 53). O Direito vai além dos textos jurídicos constituídos por aqueles que, por ora, influenciaram ou tinham poder legitimado para tanto, de modo sua construção pressupõe uma participação democrática, em que os mais diversos sujeitos estejam envolvidos (COSTA, 2018, p. 180).

A territorialização dos alimentos deve ser constituída por cada territorialidade e sua cultura inerente, pelos sujeitos do campo que estão em constante busca, através de lutas e movimentos sociais, de uma vida agrária mais justa e digna para todos aqueles que sobrevivem da terra. Toda essa processualidade é que resultará na normatização e consequente positivação dos anseios de tais sujeitos, das suas normas sociais já existentes, e até mesmo possibilitarão a reivindicação por liberdade e justiça que vá de encontro com o próprio ordenamento já positivado (PEREIRA, 2008, p. 24). O direito dos sujeitos coletivos de direito é assim achado e construído pelos próprios e diversos sujeitos tradicionais do campo, em suas zonas de vivência.

\section{REFERÊNCIAS BIBLIOGRÁFICAS}

CAMACHO, Rodrigo Simão. A barbárie moderna do agronegócio versus a agricultura camponesa: implicações sociais e ambientais. GeoGraphos. Revista Digital para Estudiantes de Geografia y Ciencias Sociales. 2012.

CLAVERO, Bartolomé. Constitucionalismo Global. Por uma história verossímil dos direitos humanos. $1^{\mathrm{a}}$ edição. Editora Palavrear. Goiânia. 2017.

COSTA, Alexandre Bernardino. ROSSI, Amélia Sampaio. Poder constituinte e democracia no constitucionalismo contemporâneo: o direito achado na rua. P. 157-181. Disponível em: <https://ppgidh.ndh.ufg.br/up/788/o/Cap\%C3\%ADtulo_de_Livro_Publicado.pdf\#page=15 7>. Acesso em: 12 de julho de 2018.

DERANI, Cristiane. Alimento e biodiversidade: fundamentos de uma normatização. Hiléia: Revista de Direito Ambiental da Amazônia. Manaus, Ano 3, no 4, p. 53 - 86, 2006.

FERNANDES, Bernardo Mançano. Soberania alimentar como território. In: TARREGA, Maria Cristina Vidotte Blanco e SCHWENDLER, Sônia Fátima. Conflitos agrários: seus sujeitos, seus direitos. Goiânia. Editora da PUC Goiás. p. 29-52. 2015.

FERNANDES, Bernardo Mançano. Sobre a tipologia de territórios. Disponível em: http://acciontierra.org/IMG/pdf/BERNARDO_TIPOLOGIA_DE_TERRITORIOS.pdf. Acesso em: 27 de julho de 2018. 
FILHO, Roberto Lyra. O que é o direito. 11ª edição. Editora Brasiliense. São Paulo. 1982.

FILHO, Roberto Lyra. Direito do capital e direito do trabalho. Editora Fabris. Porto Alegre. 1982.

FLORES, Joaquin Herrera. A (re)invenção dos direitos humanos. Editora Fundação Boiteux. Florianópolis. 2009.

FLORES, Joaquin Herrera. Os direitos humanos no contexto da globalização: três precisões conceituais. Revista Lugar Comum, $\mathrm{n}^{\mathrm{o}}$ 25-26, p. 39-71. Disponível em: <http://www.forumjustica.com.br/wp-content/uploads/2013/02/aula-17_Joaquin-DHs.pdf>.

Acesso em: 23 de julho de 2018.

FLORES, Joaquín Herrera. Los derechos humanos como produtos culturales - crítica del humanismo abstracto. Los libros de la catarata, Madri. 2005.

GOHN, Maria da Glória. Teorias sobre os movimentos sociais: o debate contemporâneo. Disponível em: < www.sbsociologia.com.br/portal/index.php?option=com_docman\&task..>. Acesso em: 22 de agosto de 2018.

HONNETH, Axel. Luta por reconhecimento: a gramática moral dos conflitos sociais. São Paulo: Editora 34. 2003.

JÚNIOR, José Geraldo de Souza. Direito como Liberdade: O Direito Achado na Rua. Experiências Populares Emancipatórias de Criação do Direito. 2008. Tese (Doutorado). Programa de Pós Graduação em Direito da Universidade de Brasília (UnB). Brasília. 2008.

MENDONÇA, Maria Luisa Rocha Ferreira de. Modo capitalista de produção e agricultura: a construção do conceito de agronegócio. 2013. Tese (Doutorado) - Programa de Pós Graduação em Geografia Humana, da Faculdade de Filosofia, Letras e Ciências Humanas, da Universidade de São Paulo (USP). São Paulo. 2013.

NETO, João da Cruz Gonçalves; NETO, Pedro Felippe Tayer. Transformações do direito e desenvolvimento agrário na sociedade de risco. Revista do Direito Unisc, Santa Cruz Do Sul. $\mathrm{N}^{\mathrm{o}}$ 41, p. 24 - 40. Nov./Dez. 2013.

PEREIRA, Leandro Silveira. Basta de falar em crise! Entrevista José Geraldo de Sousa Júnior. Revista Getúlio. Jan. 2008.

PORTO-GONÇALVES, Carlos Walter. A globalização da natureza e a natureza da globalização. $7^{\mathrm{a}}$ edição. Rio de Janeiro. Civilização Brasileira. 2017.

PORTO-GONÇALVES, Carlos Walter. Geografia da riqueza, fome e meio ambiente: pequena contribuição ao atual modelo agrário/agrícola de uso de recursos naturais. Revista Interthesis. p.1-55. 2004.

SANTILLI, Juliana. Agrobiodiversidade e direitos dos agricultores. São Paulo: Editora Peirópolis. 2009. 
SANTOS, Boaventura de Sousa. Reiventar a democracia. Edição Gradiva. Lisboa. $2^{\mathrm{a}}$ edição. Abril/2002.

SANTOS, Milton. A natureza do espaço: espaço e tempo: razão e emoção. $4^{\text {a }}$ edição. São Paulo. Editora da Universidade de São Paulo, 2006. p. 156-176.

SOUSA, Nair Heloisa Bicalho de., et. al. O direito achado na rua: 25 anos de experiência de extensão universitária. Disponível em: <http://periodicos.unb.br/index.php/participacao/article/view/5971>. Acesso em: 09 de julho de 2018.

SOUZA FILHO, Carlos Frederico Marés de. Terra mercadoria, terra vazia: povos, natureza e patrimonio cultural. Revista InSURgência. Ano 1, Volume 1, número1. Brasília. Janeiro/Junho. 2015.

TRENTINI, Flávia; SARAIVA, Luciana de Andrade. Empresa rural. Revista do Curso de Direito, v. 6, n.6, p. 236-252, 2001.

ZELEDÓN, Ricardo Zeledón. Estado da arte do Direito Agrário no mundo contemporâneo. Série Desenvolvimento Rural Sustentável. Justiça Agrária e Cidadania. Volume 1. p. 11-87. Março de 2005.

ZELEDÓN, Ricardo Z. Fundamentos para uma “Teoria Pura Del Derecho Agrario" Contemporâneo (Parte II). Campo Jurídico. Vol. 2, n. 2. p. 15-48. Outubro de 2014. 